\title{
Apontamentos sobre a formação de professores nos estudos e produções do grupo de pesquisa EDUCAS/UECE: percursos e perspectivas
}

\begin{abstract}
RESUMO: O texto, resultado de exame teórico e documental, aborda o tema da formação de professores nos estudos e produções do grupo de pesquisa Educação, Cultura Escolar e Sociedade - EDUCAS, da Universidade Estadual do Ceará - UECE, entre 2006 a 2018. As últimas décadas evidenciaram o potencial de processos associativos na produção do conhecimento, fomentando a expansão e fortalecimento de grupos de pesquisa nas universidades públicas. A análise destaca a caminhada como coletivo, a adoção de formas de trabalho colaborativo e investimentos na formação de novos pesquisadores para a área, como marca do percurso do EDUCAS. O desenvolvimento de pesquisas integradas é outro aspecto recorrente nos estudos dessa equipe, prevalecendo a abordagem qualitativa, pesquisas empíricas e a adoção de metodologias variadas. As temáticas denotam interesses no campo da política educacional, do percurso de formação dos professores, da prática docente e da inovação pedagógica, tanto numa perspectiva contemporânea quanto histórica. O EDUCAS está na base da criação e consolidação do Programa de Pós-Graduação em Educação desta instituição, que tem como área de concentração a formação de professores.
\end{abstract}

PALAVRAS-CHAVE: Formação de Professores. Grupo de Pesquisa. Metodologia

\section{Notes on teacher training in the studies of UECE research group EDUCAS: pathways and perspectives}

\begin{abstract}
The text, result of a theoretical and documentary exam, addresses the theme of teacher training in the studies and productions of the research group Educação, Cultura Escolar e Sociedade (Education, School Culture and Society) - EDUCAS, of the State University of Ceará - UECE, from 2006 to 2018. The scientific and technological progress of the last decades has highlighted the potential of associative processes in the production of knowledge in the most various areas, a movement that has encouraged the expansion and strengthening of research groups within public universities. The analysis evidenced the option to move as a collective as a mark of EDUCAS 'constitution, with the adoption of collaborative work forms and focused on the formation of new researchers for the area. The development of integrated research is another recurrent aspect in the studies of the first decade of existence of this team, prevailing the qualitative approach, empirical researches and the adoption of varied methodologies. The themes denote interests in the field of educational policy, of the teacher training pathway, teaching
\end{abstract}


practice and pedagogical innovation, addressed both in a contemporary and historical perspective. EDUCAS is one of the teams in Education of UECE registered in the CNPq Directory of Research Groups, in the basis of the creation and consolidation of the Graduate Program in Education of this institution, which focuses on teacher training. Its contribution is delineated in the strengthening of the History and Educational Evaluation thematic nucleous, of the research line "Training and Educational Policies" and in the constitution of the research line "Training and Professional Development in Education" of this strictosensu postgraduate program, especially in the articulation that promotes between researchers in the scope of Basic Education, undergraduate and postgraduate programs. The volume of theses, dissertations, monographs, articles and books published by members of the research group evidences the potential of the associative process based on the collaborative work among peers, beginners and veterans, in the world of scientific research.

KEYWORDS: Teacher Training. Research group. Methodology 


\section{INTRODUÇÃO}

O potencial de processos associativos na produção do conhecimento nas mais diversas áreas tem se revelado uma tendência da ciência contemporânea, movimento que agregou valor a constituição de estudos em grupos. No contexto brasileiro essa tendência é impulsionada, entre outros fatores, pelo crescimento da pós-graduação stricto sensu, expressando-se no aglutinamento de pesquisadores experientes e iniciantes, que trabalham em colaboração e organizados em torno do que se convencionou, a partir das orientações do CNPq, de Grupos de Pesquisa. Esta composição, segundo Moreira, Vilan Filho e Mueler (2015, p. 95), se caracteriza "pelo compartilhamento ideológico, com condutas baseadas em normas, valores e crenças, e com relação interdependente entre os seus membros".

De acordo com o CNPq, a noção de grupo de pesquisa remete a "um conjunto de indivíduos" organizados e envolvidos, profissional e permanentemente, com atividades de pesquisa estruturadas em torno de linhas comuns de investigação e que, em alguma medida, compartilha instalações e equipamentos. Esta agência de fomento esclarece, ainda, que o "fundamento organizador" desse processo associativo é a liderança de um pesquisador com experiência, destaque e reconhecimento no campo científico ou tecnológico. Tal definição reforça a características aludidas por Moreira, Vilan Filho e Mueler (2015)

A centralidade dos processos associativos por meio de Grupos de Pesquisa nas atividades de produção de conhecimentos como resultado de investigação científica manifesta-se, também, no interesse dos pesquisadores brasileiros em registrarem suas equipes no Diretório de Grupos de Pesquisa (DGP) do Conselho Nacional de Desenvolvimento Científico eTecnológico (CNPq). O crescimento do total de grupos de pesquisa no Brasil cadastrados nesse repositório é uma evidência nessa direção: de 11.760, em 2000, para 27.523, em 2010 (um salto de quase 150\%), chegando a 2014 com 35.424 grupos em atividade (FURTADO, 2016). Não há dúvida de que os pesquisadores brasileiros reconhecem que este repositório propicia visibilidade a produção e às especificidades de seus grupos junto a comunidade científica nacional e internacional.

Este comportamento associativo, estimulado a princípio por meio da composição de grupos de pesquisa, abre fendas na prática da pesquisa individual, fazendo caminho para o processo de "transição para o 'modo 2 de produção do conhecimento', marcado pelo trabalho em rede, tal como caracterizado pelo Plano Nacional de Pós-Graduação 2011-2020 (BRASIL, 2010). Sob este prisma, a emergência e expansão da associação de pesquisadores em torno de grupos de pesquisa, pode ser identificado como a 'nascente' do que o CNPq e demais agências de fomento da ciência, tecnologia e inovação no país reconhecem como modelo mais apropriado para enfrentar os desafios da pesquisa e produção de conhecimento na contemporaneidade.

A associação e o trabalho colaborativo entre pesquisadores, em distintos contextos e articulado em torno do compartilhamento de temáticas e dados, estão no cerne do sentido que o termo "rede" evoca no campo da pesquisa. Este entendimento alinha-se a definição registrada no Dicionário Houaiss da Língua Portuguesa (HOUAISS e VILLAR, 2009, p. 1.627), que remete a ideia de entrelaçamentos, de um "conjunto de pontos que se comunicam entre si" ou de "pessoas, órgãos ou organizações que trabalham em conexão, com um objetivo comum".

O sentido metafórico de rede, recorrendo aos apontamentos de Machado (2001, p. 337), passa a ser adotado também como representação do conhecimento, indicando ruptura com o sentido cartesiano com que fora concebido, ancorado em premissas como ordem pré-estabelecida ou a lógica do mais simples ao mais complexo, assumindo um sentido em que: "[...] conhecer é como enredar, tecer significações, partilhar 
significados. Esta compreensão, é importante que se registre, não repercute apenas na "forma de representação do conhecimento", mas implica, sobretudo, "uma mudança epistemológica e teórico-metodológica, um outro modo de conceber e produzir conhecimento e se colocar como pesquisador nesse processo, o que demanda sair do isolamento, pesquisar em colaboração e explorar as diversas expertises de cada indivíduo e ou grupo de pesquisa que compõem o conjunto de pesquisadores" (FARIAS et al., 2018, p. 30).

São notáveis os resultados da associação e colaboração de pesquisadores nas diversas áreas, em particular na Educação, tanto na produção de conhecimento mais abrangente e aprofundado quanto na formação de novos pesquisadores. É o que buscamos evidenciar neste texto, que tem como objetivo examinar o tema da formação de professores nos estudos e produções do grupo de pesquisa Educação, Cultura Escolar e Sociedade (Educas) no período de 2006 a 2018, equipe cadastrada no Diretório de Grupos de Pesquisa do CNPq e vinculada a Universidade Estadual do Ceará (UECE).

\section{EDUCAS: A PRODUÇÃO DE UM PERCURSO}

O percurso de produção dessa equipe está ligado à prática social constituída no âmbito da atuação profissional de professores da UECE, universidade pública com trajetória de tradição na formação de recursos humanos especializados nos mais diversos campos do conhecimento no Estado, sobretudo à formação de professores (FARIAS et al., 2011). Situada no Nordeste do Brasil, região que concentra cerca de $20 \%$ dos grupos de pesquisa cadastrados no CNPq, esta instituição se destaca na cena nacional como a melhor universidade estadual do Norte, Nordeste e Centro-Oeste do Brasil, pelo sétimo ano consecutivo (RUF, 2017).

Reporta-se aqui a ideia de 'produção' no sentido filosófico que este vocábulo assume, isto é, de "ser alguma coisa que poderia não ser" ou, ainda, "como qualquer possibilidade que se torne causa de geração de coisas que antes não existiam" (ABBAGNAMO, 2000, p. 798). Este sentido nos parece pertinente para revisitar as marcas da caminhada do EDUCAS nos seus doze primeiros anos de existência.

Um pequeno livro organizado no início da década de 2000, intitulado "Pesquisa em Educação na UECE: um caminho em construção" (CAVALCANTE, NUNES e FARIAS, 2002), destacava a saída do isolamento dos pesquisadores e sua congregação em torno de grupos de pesquisa como uma evidência da mudança substancial de mentalidade na pesquisa desenvolvida nesse contexto institucional. Esse movimento é esclarecido nos seguintes termos: "Para se ter uma idéia do que isso significa em termos de crescimento na pesquisa educacional na UECE, tomando dados do Diretório de Grupos de Pesquisa do CNPq, passamos de nenhum grupo de pesquisa cadastrado em 1996 para quatro grupos em atividade no ano de 2000 - Formação de Professores; Planejamento, Política e Gestão Educacional; Paradigmas da Educação a Distância; Trabalho, Educação e Luta de Classe. Cada um desses grupos carrega sua própria história, reflexo da trajetória pessoal e profissional dos pesquisadores que os compõem" (CAVALCANTE, NUNES e FARIAS, 2002, p. 7).

O Educas decorre de desdobramentos do grupo de pesquisa "Formação de Professores" em meados de 2005, decorrente da ampliação e diversificação de interesses temáticos de seus pesquisadores. Desde a tomada da decisão de criar um grupo de pesquisa, sua estruturação acadêmica e física, até sua regularização no âmbito da universidade, decorreram dezoito meses. A certificação de "grupo reconhecido pela instituição" no Diretório do CNPq remonta a 15/12/2006, data que demarca seu nascimento institucional.

Quando iniciou suas atividades essa equipe era integrada por cinco pesquisadores que, desde meados dos anos 1990, vinham investindo no fomento e fortalecimento de uma cultura de pesquisa em educação na 
UECE, quer desenvolvendo estudos na área (FARIAS, 1997; BEZERRA, 1996; MAGALHÃES JUNIOR, 2003; LIMA NUNES, 1995), quer participando de programas de iniciação científica. Todos, então, recém doutores em educação e iniciando a docência universitária. No momento de sua institucionalização o escopo dos estudos do Educas assume como eixo de análise o processo escolar, considerando as dimensões da política, da cultura, da docência e da aprendizagem no contexto de suas determinações sociais e históricas. Com base nesse foco suas linhas de pesquisa foram assim definidas:

a) Formação Docente, Desenvolvimento Profissional e Aprendizagem - investiga as ideias, valores, crenças, saberes e práticas da escola e dos sujeitos que a integram, destacando o professor em sua formação, desenvolvimento profissional e pessoal, bem como os processos de aprendizagem que ocorrem na escola sob a perspectiva sócio-histórica e cultural;

b) Política, Planejamento e Gestão da Educação - estuda a política e a gestão educacional a partir da reestruturação do Estado e seus desdobramentos no projeto educativo em curso, percebendo as relações/ articulações entre sistema e escola;

c) História da Educação e Cultura Escolar - investiga a história da educação no Brasil e no Ceará em sua relação com a cultura nacional, buscando compreender a constituição dos modelos educacionais implantados no país, as práticas das instituições escolares e seus sentidos histórico-culturais na construção da profissão docente.

Dos cinco pesquisadores fundadores e onze bolsistas de iniciação científica que começaram essa caminhada, o Educas, em doze anos de funcionamento, incorporou novos pesquisadores, foi compondo redes com outros grupos e instituições (UNILAB, UFC, UFPI, UFOP, UNIFESP), agregando professores da Educação Básica vinculados a rede pública de ensino, doutorandos, mestrandos e graduandos. O grupo, que dispõe e compartilha de estrutura física equipada, possui também um blog na web (http://educas.com.br/blog/) onde disponibiliza dados e resultados de pesquisa, publiciza a participação em eventos e outras atividades de pesquisa e divulgação científica.

O processo de pesquisa e produção do conhecimento no âmbito desse grupo de pesquisa, em seus 12 anos de existência, foi nutrido pelo que Hargreaves (1999, p. 218) chama de "cultura da colaboração", na qual as relações de trabalho tendem a ser "espontâneas, voluntárias, orientadas para o desenvolvimento, imprevisível e não circunscritas apenas aos horários de atividade". Com efeito, no Educas elas foram caracterizadas pelo estabelecimento de relações que emergiram de iniciativas internamente propostas e externamente induzidas, e, mesmo não tendo sido impostas por uma hierarquia superior, precisaram superar limitações do ambiente de trabalho, tendo recebido apoio tímido por parte do poder administrativo da instituição. Os resultados desse processo associativo pautado na colaboração, considerando a produção bibliográfica de seus integrantes, os indicadores relacionados a formação de novos pesquisadores em educação (iniciação científica e pós-graduação stricto sensu) e a continuidade e aprofundamento de estudos desenvolvidos no âmbito do grupo, mostram que essa é uma alternativa potente no enfrentamento dos desafios contemporâneos da pesquisa e produção do conhecimento.

Nesses termos, e recorrendo ao sentido metafórico de rede em relação à produção de conhecimento, priorizou-se no Educas uma forma de organização e desenvolvimento do trabalho de pesquisa que favorecesse a interlocução, produção e intercâmbio entre pesquisadores e instituições; a atuação dos integrantes da equipe como coletivo, participando, desde as decisões teóricas e metodológicas fundamentais para o seu 
desenvolvimento aos encaminhamentos mais operacionais em torno do objeto de estudo; e que também contribuísse para a formação de seus pesquisadores iniciantes e mais experientes.

O percurso metodológico do grupo de pesquisa Educas, portanto, foi buscar sua seiva no trabalho colaborativo, aqui aludido não como referência à produção de dados, mas sim a estruturação e a organização do grupo de pesquisa como rede de pesquisa numa perspectiva de decisões compartilhadas. Uma prática investigativa assim organizada, sobretudo quando envolve pesquisadores iniciantes e sêniores e com distintas formações, requer discussão, confrontação de idéias, rupturas com práticas individualistas e competitivas, ou, como ressaltado por Esteves (2018, p. 16), solicita que cada integrante "saia do seu casulo" para que se possa afinar a "linguagem, dos conceitos mobilizados" e as "conotações que Ihes atribuímos". Este movimento é complexo, delicado e exigente do ponto de vista cognitivo e emocional.

\section{A FORMAÇÃO DE PROFESSORES NAS PESQUISAS E PRODUÇÕES DO EDUCAS}

A formação de professores enquanto objeto de estudo está diretamente imbricada a trajetória profissional e de formação dos pesquisadores fundadores do Educas, interface que corrobora a asserção de Mills (1969, p. 239) de que, na prática, jamais se começa a trabalhar num projeto: sempre se está "trabalhando, seja num veio pessoal, nos arquivos, nas notas tomadas aos rascunhos, ou nos empreendimentos dirigidos".

Estar imerso neste movimento é o que nos permite perceber a revisitação que fazemos aos estudos produzidos em diversos momentos da trajetória do Educas, que encontra no desenvolvimento de projetos de pesquisa integrados suporte primordial para consolidar o processo associativo iniciado em 2006 pelos pesquisadores desse grupo. Esta caminhada se amplia e se diversifica nos anos seguintes, quando se registra estudos mais dirigidos ao escopo da linha de pesquisa a qual cada pesquisador está vinculado, movimento também estimulado por sua atuação no Programa de Pós-Graduação em Educação da UECE que, em 2006, encontrava-se em seu primeiro triênio de avaliação da CAPES. Havia naquele momento histórico, por conseguinte, uma expectativa institucional em torno do crescimento e diversificação das frentes de investigação dos grupos de pesquisa ligados a esse programa, e o EDUCAS era um deles.

\subsection{DESENVOLVER PESQUISA INTEGRADA - VIA PARA CAMINHAR COMO COLETIVO}

A princípio, os estudos realizados no âmbito do Educas assumiram a feição de pesquisa integrada, estruturada agregando, ao mesmo tempo, os interesses temáticos individuais de seus pesquisadores articulados por um fio condutor comum. Este desenho, de projeto integrado de pesquisa, ao propiciar a sintonia entre o individual e o coletivo, favoreceu o fortalecimento interno dos pesquisadores dessa equipe, o estabelecimento de uma dinâmica de trabalho e negociação da pesquisa passo a passo.

A pesquisa "Profissão Professor: políticas e memórias" (PROPEM), aprovada pelo Edital Universal n 19/2004 do CNPq, foi a primeira desenvolvida a partir da institucionalização do EDUCAS e envolvia todos os pesquisadores do grupo, caracterizando-se como uma iniciativa integrada, conforme a pouco denominado. A profissão professor, abordada a partir das políticas e memórias de docentes, delineou-se como fio condutor comum, permitindo tanto o diálogo abrangente quanto mais focalizado de questões afetas ao tema geral da investigação, criando espaço para a discussão entre pesquisadores e decisões compartilhadas.

Esse estudo investigou a profissão docente no Ceará no período de 1930 a 1964 considerando três ângulos de análise, cada um constituindo um subprojeto: Estudo 1 -A profissão docente no discurso governamental 
1930/1964; Estudo 2 - A política educacional expressa nas ideias e práticas de educadores cearenses; Estudo 3 - A Escola Normal Rural de Juazeiro do Norte: tramas do cotidiano na construção da profissão docente no Ceará. Essa pesquisa, a primeira do Educas, contou com financiamento externo, teve vigência de 07/2005 a 06/2007 e envolveu, a época, seus cinco pesquisadores fundadores (FARIAS et al., 2007).

Essa iniciativa abordou a profissão docente numa perspectiva histórica (LE GOFF, 1996; THOMPSON, 1998), tomando como referência as políticas educacionais implementadas no contexto cearense durante o intervalo temporal assinalado. Apoiou-se no pressuposto de que a política educacional não é resultado somente da ação estatal, mas também do papel exercido pelos demais sujeitos envolvidos em sua concretização (SHIROMA, MORAIS e EVANGELISTA, 2000; PERONI, 2003). Nesse sentido, a problemática da pesquisa centrou-se na forma e nos significados das políticas educacionais no que se refere ao discurso governamental acerca da docência, ao sentido particular que tal discurso tomou na prática de educadores que vivenciaram esse momento histórico e ao lugar ocupado pela Escola Normal Rural de Juazeiro do Norte, a primeira do Brasil, na produção de uma cultura profissional em relação à atividade docente nesse contexto.

No que concerne aos aspectos metodológicos, a investigação recorreu a múltiplas fontes e procedimentos, com apoio nos pressupostos da abordagem qualitativa na produção e análise dos dados de cunho histórico. Assim, considerando a intencionalidade de cada estudo, estes recorreram a procedimentos diferenciados e diversos visando à produção de uma síntese interpretativa que permitisse compreender os "sentidos concretos" (KOSIK, 1976) da profissão professor no espaço-tempo em foco. No Estudo 1 recorreu-se a análise documental, considerando as seguintes fontes: a legislação que trata da educação (constituições estaduais, leis e decretos), as Mensagens Governamentais e o Relatório de Atividades (1931-1934). No Estudo 2 optou-se pela história de vida temática, modalidade da história oral, de 7 educadores cearenses. A produção dessas narrativas orais focalizou a trajetória profissional desses profissionais, nele destacando dois componentes: as idéias e as práticas que marcaram esta experiência. Para a análise buscou-se, ainda, o suporte do AQUAD 5.0, programa informático que auxilia o exame de dados qualitativos. O Estudo 3 trabalhou com a identificação de documentos impressos sobre a Escola Normal Rural de Juazeiro do Norte, boa parte oriundo do acervo pessoal de Maria Assunção Gonçalves (ex-aluna da segunda turma da Escola Normal Rural de Juazeiro e antiga professora), e relatos orais de professores e alunos egressos da Escola Normal Rural de Juazeiro do Norte. A análise indutiva permitiu a definição de categorias.

O PROPEM favoreceu situações, espaços de interação e trocas extremamente produtivos para este grupo de pesquisadores, valorizando o investimento que estes vinham realizando desde o final dos anos 1990 no fomento da cultura de pesquisa em educação na UECE (CAVALCANTE, NUNES e FARIAS, 2002). Seu desenvolvimento oportunizou a 15 alunos da licenciatura em Pedagogia dessa instituição a vivência teórico-prática da pesquisa em educação, fundamental à sua formação, tornando concreto o princípio da indissociabilidade entre a formação para a docência, a gestão educacional e a produção de conhecimentos, como prevê as diretrizes curriculares desse curso.

A formação em pesquisa desses graduandos fomentou o interesse pela investigação científica e pelo tema da política educacional, em particular, por questões relacionadas à formação de professores e à história da educação cearense. A produção de seis monografias de conclusão do Curso de Pedagogia é expressiva dessa contribuição (NOGUEIRA, 2005; SILVA, 2007; CASTRO, 2007; CONCEIÇÃO, 2007; GURGEL, 2008; AGUIAR, 2007). Um grupo de cinco das autoras desses trabalhos monográficos, nos anos seguintes, ingressaram e concluíram o curso de mestrado em educação. Desse grupo destaca-se, ainda, a publicação de seus trabalhos dissertativos em forma de livro (SILVA, 2011; NOGUEIRA, 2011). 
A participação em 12 eventos científicos com apresentação de trabalhos; a sistematização de 3 (três) bancos de dados contendo informações sobre a profissão professor no Ceará (A Profissão Docente no Discurso Governamental 1930-1964: Detalhamento das Fontes; Trajetórias Profissionais de Educadores Cearenses; Cenas do Cotidiano Escolar Rural), socializados no blog do EDUCAS; e a publicação de textos completos (FARIAS e NUNES, 2006; MAGALHÃES JUNIOR e FARIAS, 2006, 2007; FARIAS e BEZERRA, 2011), são alguns dos resultados dessa investigação integrada que, como registrado anteriormente, fortaleceu o sentimento de pertença de seus pesquisadores, os fez dialogar visando afinar a linguagem, os conceitos mobilizados e os sentidos atribuídos por cada um, e fomentou uma caminhada como coletivo.

O investimento em estudos aprofundando temáticas relacionadas aos interesses específicos de cada pesquisador do Educas se faz a partir dessa primeira investigação integrada.

\subsection{PESQUISAS DA LINHA “FORMAÇÃO DOCENTE, DESENVOLVIMENTO PROFISSIONAL E APRENDIZAGEM"}

O interesse em aprofundar estudos acerca dos elementos identitários constitutivos da docência como atividade profissional no Ceará levou integrantes da linha de pesquisa "Formação Docente, Desenvolvimento Profissional e Aprendizagem" a empreenderem, entre os anos de 2007 a 2009, a pesquisa "Modos de ser professor: pelos labirintos da docência no Ceará", iniciativa que contou com o apoio da Fundação Cearense de Apoio ao Desenvolvimento Científico e Tecnológico do Estado (FUNCAP).

Esta investigação, desdobramento de outras incursões sobre a política educacional e o ser professor cearense, retomou relatos ainda não explorados de estudo anterior. $\mathrm{O}$ foco sobre os modos de ser professor expressa a problemática da pesquisa, caracterizada pela análise de elementos identitários constitutivos da docência como atividade profissional no Ceará. Questionava-se: Quais as marcas constituidoras da docência dos professores cearenses pesquisados? Em torno dessa pergunta de partida vários outros questionamentos circundavam: que imagem têm os professores sobre sua profissão? Que razões levaram/motivaram para o magistério? Qual a forma de ingresso desses docentes no magistério? A que formação inicial e continuada estes professores tiveram ou têm acesso? Que valores, práticas pedagógicas e experiências profissionais caracterizam a docência desses professores? Em que condições de trabalho exercem/exerceram a docência? Quais as experiências profissionais vivenciadas no campo da docência? Quais as dificuldades enfrentadas no exercício da docência?

Dentre as possibilidades metodológicas de uso da história de vida, optou-se pelo enfoque temático, entendendo que ele permitia investigar o professor a partir das referências e circunstâncias de sua trajetória, dos modelos rejeitados ou incorporados no e para além do local de trabalho. Foram analisados relatos de 28 professores (22 mulheres e 6 homens) situados em 5 (cinco) municípios cearenses (Baturité, Icó, Limoeiro do Norte, Sobral e Viçosa). Estes relatos, produzidos por meio de entrevistas narrativas, foram gravados em áudio, transcritos e impressos, compondo o acervo documental do Educas.

Os dois estudos detalhados - o PROPEM e o Modo de Ser professor, por diferentes caminhos, teceram novos focos de interesse, especialmente pelo que evidenciou sobre as buscas dos professores cearenses em relação a sua formação, a relevância que assume nesse processo o acesso a Educação Superior e o anseio pela pesquisa como alternativa de reconhecimento e possibilidade de aprender mais e melhor. A relação ensino e pesquisa no processo formativo de professores se delineou, então, como uma temática que possibilita ampliar a discussão sobre a construção da identidade profissional do professor, fomentando 
a abertura de novas frentes de estudos, no caso a pesquisa "A cultura docente face à formação para a pesquisa: a gestão dos saberes na docência universitária", apoiada pelo Edital Universal do CNPq n 14/2008 e realizada no período de 12/2008 a 06/2011.

Com esta investigação interinstitucional amplia-se o processo associativo em curso, desta feita compondo um desenho investigativo agregando três grupos de pesquisa cadastrados no Diretório do CNPq: Educação, Cultura Escolar e Sociedade (da UECE/Centro de Educação); Educação e Saúde Coletiva (da UECE/Centro de Ciências da Saúde); e, Saber e Prática Social do Educador (da UFC/ Faculdade de Educação). Seu desenvolvimento foi norteado pelos seguintes questionamentos: Que práticas pedagógicas desenvolvem os docentes com vínculo com pesquisa que atuam em cursos de graduação na UECE? Que estratégias de ensino utilizam para iniciar o aluno na elaboração do conhecimento? Como enfrentam as dificuldades no percurso da ação docente? Como entender a prática pedagógica desses professores sob o referencial do sujeito reflexivo, crítico e transformador? (FARIAS, 2011).

A iniciativa, com esteio nos fundamentos da abordagem qualitativa e com feição empírica, abrangeu 10 cursos de graduação da UECE e um total de 18 professores, todos com algum tipo de vínculo com pesquisa no exercício de suas funções docentes na Educação Superior (ministravam disciplinas no campo da investigação científica e/ou desenvolviam projeto de pesquisa e/ou participavam de grupo de pesquisa). Teve como objetivo compreender a ação docente universitária em situação de ensino e sua relação com as orientações curriculares que recomendam a pesquisa como elemento importante da formação de nível superior.

O referencial teórico da investigação, respaldado nos estudos sobre a epistemologia da prática, o currículo em ação, a racionalidade na produção de conhecimentos e a pesquisa como elemento articulador do ensinar e do aprender, permitiu entender o docente como sujeito que edifica sua ação mediante as relações que estabelece no seu contexto de trabalho, as quais podem ser explicitadas por meio de seus "discursos práticos" (falas e ações). O desenvolvimento do estudo, que envolveu pesquisadores, doutorandos, mestrandos e graduandos. A análise indutiva permitiu a definição de categorias no exame da documentação, bem como o uso de programa de análise de dados qualitativos (NVIVO 9).

Essa investigação propiciou desdobramentos diversos, fomentando o desenvolvimento da pesquisa "O Professor do Ensino Superior e a Pesquisa: Qual relação e prática pedagógica?" (SILVA, 2011), coordenador por integrante do Educas. Apoiada pela Fundação Cearense de Apoio ao Desenvolvimento Científico e Tecnológico (FUNCAP), essa iniciativa, analisou a prática docente e sua relação com a pesquisa no âmbito do Ensino Superior, questionou: Que práticas pedagógicas desenvolvem os docentes que não mantêm relação direta com atividades de pesquisa? Que estratégias de ensino utilizam para iniciarem o aluno no processo de construção do conhecimento? Assumiu, portanto, como objeto de estudo a prática pedagógica dos docentes universitários que não mantêm relação direta com atividades de pesquisa, adotou a Universidade Estadual do Ceará como campo de estudo, caracterizando-se como uma pesquisa qualitativa empírica, do tipo estudo de caso.

A incursão fomentou, ainda, nos anos subseqüentes, outras duas iniciativas: as pesquisas "Os Cursos de Licenciatura como Formadores de Professores: em que se constituem as bases de formação para a docência na Educação Básica?" (SILVA, 2014); e, "A Formação Continuada no exercício da docência em contextos da universidade: o que pensam os professores?" (SILVA, 2017), ambas apoiadas com bolsa de iniciação científica pelo CNPq e FUNCAP. Esses estudos aprofundam e dão continuidade às investigações empreendidas, por pesquisadores do Educas, sobre a docência universitária em instituições públicas. 
Parte dos resultados dos quatro últimos estudos supracitados encontra-se publicizada no livro "A docência universitária sob o prisma da integração ensino e pesquisa" (FARIAS et al., 2014) e em capítulos (NÓBREGA-THERRIEN, FARIAS e SILVA, 2017; CARDOSO e FARIAS, 2017, ARAÚJO e FARIAS, 2017; SILVEIRA, NÓBREGA-THERRIEN e AZEVEDO, 2017) da obra "Formação e Desenvolvimento Profissional em Educação," organizada a partir da parceria EDUCAS/UECE e UFMA por membros do EDUCAS (FARIAS, NÓBREGA-THERRIEN e MORAES, 2017).

Outra investigação que possibilitou aprofundar análises de interesse dos pesquisadores do Educas foi o estudo exploratório acerca do Pibid no Estado do Ceará, realizado com apoio da Secretaria de Educação Básica do Ceará (SEDUC) e da Fundação Cearense de Apoio ao Desenvolvimento Científico e Tecnológico (FUNCAP). A iniciativa, intitulada "Melhoria da aprendizagem na escola de Ensino Médio: avanços, limites e perspectivas do PIBID no cenário da avaliação censitária", foi desenvolvida em 2011 (FARIAS e BEZERRA, 2011). A proposta visou investigar, a partir da perspectiva da comunidade escolar, a interface do Programa Institucional de Bolsa de Iniciação à Docência (Pibid) com a melhoria do ensinar e do aprender em escolas cearenses de Ensino Médio com baixo desempenho em avaliações censitárias. Este propósito incidiu sobre dois focos: a) a execução do programa enquanto política voltada tanto a formação de docentes para a Educação Básica quanto para a melhoria da qualidade do ensino; b) as interfaces do Pibid no incremento do ensino e da aprendizagem nas escolas de Ensino Médio.

Com suporte na pesquisa qualitativa, recorreu ao estudo de caso, contemplando 25 escolas estaduais (Editas do Pibid 2007 e/ou 2009), localizadas em 11 municípios cearenses (Fortaleza, Maracanaú, Quixadá, Juazeiro do Norte, Barbalha, Iguatu, Icó, Varzea Alegre, Itapipoca, Forquilha e Sobral). Participaram do estudo os seguintes sujeitos: diretor da escola, coordenador pedagógico, alunos do Ensino Médio, professores supervisores, coordenadores de área do Pibid e licenciandos participantes do programa. Foram realizadas observações no contexto escolar, entrevistas individuais semiestruturada com os diretores, coordenadores pedagógicos, professores supervisores e coordenadores de área do PIBID, ao passo que com os alunos do Ensino Médio e os licenciandos foram realizados grupos focais. Análise resultante desse estudo encontra-se publicada por Rocha, Falcão e Farias (2015), no livro "Aprender a ser professor: aportes de pesquisa sobre o Pibid" (FARIAS, JARDILINO e SILVESTRE, 2015).

O conjunto desses estudos culminou com o desafio de um novo salto no processo associativo em andamento no âmbito do Educas, de início marcado por um movimento interno, congregando pesquisadores do mesmo campo disciplinar, centro e universidade, com o objetivo explícito de fomentar uma cultura de pesquisa no micro contexto da área de atuação profissional na instituição; em um segundo momento registra-se movimento associativo reverso, de dentro para fora, abrindo novas fronteiras interna e externamente, numa perspectiva interinstitucional, o que se explicita na aproximação também a pesquisadores e grupos de pesquisa de outras instituições.

Esses movimentos contínuos de associação, ao fortalecerem os pesquisadores dessa equipe e impulsionarem ações associativas mais abrangentes, resultaram no delineamento, em meados de 2012, da pesquisa em rede "Desenvolvimento Profissional Docente e Inovação Pedagógica: estudo exploratório sobre contribuições do Pibid", que consorciou três grupos de pesquisas (EDUCAS/UECE; FOPROFI/UFOP; GEPEPINFOR/UNIFESPGuarulhos) ligados a programas de pós-graduação stricto sensu situados no Nordeste e Sudeste do Brasil. A investigação, apoiada pelo Programa Observatório da Educação (CAPES Edital nº 049/2012), teve duração de 57 meses, a contar de 3/2013 (FARIAS, JARDILINO e SILVESTRE, 2012).

A pesquisa em rede "Desenvolvimento Profissional Docente e Inovação Pedagógica" analisou a relação entre a experiência vivenciada por professores da Educação Básica no âmbito do Programa Institucional de Bolsa 
de Iniciação à Docência (Pibid) e o seu desenvolvimento profissional. Seu desenho condensou indagações sobre como os professores se desenvolvem, reconhecendo o Pibid como experiência que movimenta o desenvolvimento profissional de professores da Educação Básica que dele participam como supervisores.

Uma investigação qualitativa, empírica e que recorreu a entrevista semi-estruturada com 90 professores da Educação Básica que atuaram como supervisores no Pibid no Ceará, São Paulo e Minas Gerais. Seu desenvolvimento abrangeu três etapas: I - Levantamento de fontes secundárias sobre o tema; II - Levantamento de dados primários; III - Análise e consolidação dos dados. Na primeira fase, as ações focalizaram o estudo das fontes secundárias sobre o tema, a identificação dos projetos institucionais de Pibid, das escolas e professores contemplados pelo Programa em cada Estado. Na segunda, além das sessões de estudo, foram coletados dados gerais sobre os professores supervisores; elaborado o protocolo e instrumentos da pesquisa para produção de dados primários - formulário eletrônico e entrevista semi-estruturada; realizado o levantamento e a análise dos dados primários produzidos por meio do questionário eletrônico; ministradas oficinas sobre a utilização do software NVIVO; realizada as entrevistas junto aos 90 professores da Educação Básica (30 para cada Estado), transcrição e conferência desse material. A terceira foi marcada pelo uso do NVIVO no tratamento dos dados, o que foi feito a partir da estruturação de um único do projeto analítico no software, medida que visou assegurar a triangulação das informações produzidas e sistematizadas pelos três Núcleos (UECE, UFOP e UNIFESP-Guarulhos).

O percurso de desenvolvimento dessa investigação multicêntrica evidenciou que processos associativos dessa envergadura não são simples, pois cada contexto possui peculiaridades, as equipes são heterogêneas, com ritmos e condições distintas de trabalho. Estabelecer um compasso na agenda de pesquisa, respeitando as singularidades, constituiu um desafio no âmbito dos três grupos de pesquisa. Nesse esforço, a adoção do planejamento coletivo anual das ações macro da pesquisa, envolvendo integrantes dos três Núcleos, mostrou-se uma estratégia fértil, bem como contar com o suporte das tecnologias da comunicação e da informação, em particular a internet e suas múltiplas ferramentas que asseguraram aproximação real entre os Núcleos na discussão de dados e definição dos procedimentos. A realização de reuniões utilizando a ferramenta do skype fortaleceu sobremaneira essa articulação, permitindo uma interlocução direta e vivaz entre pesquisadores que se encontram em diferentes lugares. A experiência de realização de um trabalho em conjunto, compartilhando instrumentos e referencial teórico, ação que demandou um tempo maior do que em outras situações de pesquisa na tomada de decisões, revelou-se importante na constituição de práticas colaborativas de pesquisa e na formação de jovens pesquisadores em educação.

Ao manifestar-se sobre esta experiência de pesquisa em rede, a pesquisadora portuguesa Manuela Esteves (2018, p. 18), após listar os desafios e dificuldades que esse tipo de processo associativo precisa vencer para alcançar "qualidade efetiva", asseverou que esta iniciativa "preencheu de forma notável as condições" para chegar a um "bom termo". Outros dados permitem, ainda, dimensionar a contribuição dessa iniciativa: a) contemplou 105 participantes com bolsa do Programa Observatório da Educação (CAPES), entre graduandos, mestrandos, doutorandos e professores da Educação Básica e da universidade; b) Dos 41 estudantes de graduação, um grupo de 8 ingressou, após concluir a licenciatura, no curso de mestrado, isso durante a vigência da pesquisa; c) dos 29 professores da Educação Básica participantes, 16 realizaram o mestrado; d) desses 16 professores da Educação Básica, cinco ingressaram no doutorado; e) entre os docentes que ingressaram no doutorado, um publicou sua dissertação (ROCHA, 2015); f) dos 20 discentes com bolsa de mestrado, 17 foram defendidas durante a vigência do projeto; g) das 4 bolsas de doutorado, destinadas a discentes da primeira turma do Curso de Doutorado da UECE, todas defenderam suas tese durante a vigência da pesquisa. No que concerne a produção bibliográfica oriunda dessa investigação, foram publicados 3 livros, 14 artigos em periódicos qualificados da área (1A1, 3A2, 3B1, 5B2, 1 B3 e 1B5) e 19 capítulos de livros (FARIAS, JARDILINO, SILVESTRE e ARAÚJO, 2018). 


\subsection{PESQUISAS DA LINHA POLÍTICA, PLANEJAMENTO E GESTÃO DA EDUCAÇÃO}

Esta linha de pesquisa articula o interesse de quatro pesquisadores fundadores do Educas atuantes na UECE, campus Fortaleza e Limoeiro do Norte, e na Universidade da Integração Internacional da Lusofonia Afro-brasileira - UNILAB, dedicados aos estudos sobre a política da educação cearense. A princípio, um desdobramento desse processo associativo refere-se a potência do diálogo interinstitucional entre os pesquisadores do Educas, o que, no decurso do primeiro decênio dessa equipe, fomentou a criação por parte de seus integrantes, especialmente daqueles ligados a essa linha, de uma nova equipe, também cadastrada no Diretório do CNPq (2014), no caso o grupo de pesquisa "Educação, Cultura e Subjetividade", liderado por uma das autoras desse escrito.

Assim, no intento de construir uma unidade na diversidade, considerando suas trajetórias profissionais, esses pesquisadores têm alinhado temas e referenciais em torno de um mesmo objeto de estudo, abordando-o a partir de diferentes frentes de análise. Resulta desta aproximação o delineamento de uma série de estudos acerca da adoção de mecanismos gerenciais, próprios do mundo corporativo no setor público, na seara educacional, prática corrente no âmbito da gestão na transição para o século XXI, especialmente marcada pelo movimento do burocrático ao gerencial e acompanhada por uma construção ideológica democratizante e "autogestionária".

A pesquisa "Gestão do Projeto Educativo da Escola de Ensino Médio nas Trilhas das Mudanças", apoiada pelo edital Universal MCT/CNPq 14/2007, desenvolvida no período de 2007 a 2011, é emblemática desse interesse. Esta iniciativa investigou a gestão do projeto educativo da escola de Ensino Médio, no Ceará, em face de políticas e práticas implementadas no período 1995-2006 (RAMOS, 2007). Questionou os desdobramentos operados na escola nas últimas décadas (meados de 1990), em função das propostas de modernização racionalizadora da gestão. Nesses termos, assumiu como objetivos: Analisar as mudanças das propostas de modernização da gestão, mediante processos de planejamento, da dinâmica institucional e interinstitucional adotados pelos Governos na promoção do direito ao Ensino Médio; Examinar os pressupostos teórico-metodológicos da política de modernização da gestão da escola e seus desdobramentos na democratização da Educação Escolar. Ancorada nos fundamentos da pesquisa qualitativa, o estudo encontrou suporte metodológico no estudo de caso, com ênfase na análise documental e no uso de entrevistas com segmentos diversos da escola. O recorte temporal corresponde à consolidação do projeto político de um grupo de jovens empresários cearenses que, ao assumirem o governo em 1988, apontam a educação como prioridade e definem metas para a modernização do Ceará, nos 20 anos subseqüentes.

As análises produzidas a partir dessa investigação aportaram subsídios para aprofundamento, o que se concretizou com a pesquisa "Gestão por Resultado na Educação: a responsabilização e o regime de colaboração na promoção do direito à educação no Ceará (1995-2010)" (RAMOS, 2014), também apoiada pelo Edital Universal do CNPq 13/2014, coordenada por uma das autoras desse texto.

Este estudo, finalizado em 2017, investigou a consolidação da gestão por resultados (GPR) na Educação Básica cearense mediante mecanismos de responsabilização (acountability) e de acordos de cooperação, observando tais processos junto a Secretaria de Educação Básica do Ceará (SEDUC)/Superintendência das Escolas Estaduais de Fortaleza (SEFOR) e as Coordenadorias Regionais de Desenvolvimento da Educação (CREDE) de Russas e do Maciço de Baturité, no período de 1995 e 2010. A problemática investigada orbitou em torno desse processo no âmbito da rede pública cearense. Metodologicamente o estudo encontrou suporte na abordagem qualitativa, na adoção de procedimentos variados de produção de dados, com ênfase no exame de documentos e na realização de 15 entrevistas semi-estruturadas representantes dos contextos mencionados. 
Os dois estudos detalhados, e seus desdobramentos na forma de projetos de iniciação científica, monografias e dissertações, condensam as investigações encetadas pelos pesquisadores da linha Política, Planejamento e Gestão da Educação do Educas, as quais, como já registrado, estão vinculadas e ancoram o desenvolvimento do Programa de Pós-Graduação em Educação da UECE, bem como também forjam condições que favorecem a emergência de outros dois programas acadêmicos de pós-graduação stricto sensu: o Programa de Mestrado Acadêmico Intercampi em Educação e Ensino (MAIE) e o Programa de Mestrado Interdisciplinar em Humanidades (MIH).

O primeiro, que começou suas atividades em 2013, é vinculado a UECE e articula dois de seus campi situados no interior do Ceará, no caso a Faculdade de Filosofia Dom Aureliano Matos (FAFIDAM) e a Faculdade de Educação Ciências e Letras do Sertão Central (FECLESC). O segundo, que iniciou suas atividades em 2015, está vinculado a UNILAB, que busca construir uma ponte histórica e cultural para a integração/cooperação internacional entre o Brasil e países, regiões e comunidades de expressão em língua portuguesa, particularmente as africanas.

\subsection{PESQUISAS DA LINHA HISTÓRIA DA EDUCAÇÃO E CULTURA ESCOLAR}

Os estudos empreendidos no âmbito dessa linha do Educas, ao lado daqueles já detalhados nos tópicos anteriores, focalizam diferentes facetas do desenvolvimento da educação cearense e de seu professorado, abordadas, à princípio, numa perspectiva histórica. Este é o caso da pesquisa "A Escola Normal Rural de Juazeiro do Norte - tramas do cotidiano na construção da profissão docente no Ceará", uma das vertentes da pesquisa integrada PROPEM, já destacada no tópico 2.1 deste texto, e que envolveu os dois pesquisadores vinculados a essa linha do Educas.

Com o intuito de aprofundar estudos a partir do contexto local, e desde uma perspectiva histórica, desenvolveu-se, no período de 2011 a 2013, com o apoio do CNPq (bolsas de iniciação científica), a pesquisa "Cotidiano das práticas formativas de professores em Fortaleza: mitos e ritos na constituição de uma cultura profissional no período republicano" (MAGALHÃES JUNIOR, 2011). Esta iniciativa objetivou compreender o cotidiano das práticas formativas das instituições formadoras de professores em Fortaleza, os mitos e ritos contidos nas referidas práticas e seu aporte na constituição de uma cultura profissional em relação à atividade docente no período republicano.

Desdobramento dessas e de outras incursões investigativas, é o estudo "Cartografia das relações de saber/ poder dos professores das licenciaturas" (MAGALHÃES JUNIOR, 2014), que contou com o apoio financeiro do Edital Universal do CNPq 14/2014 e foi desenvolvido no período de 2014 a 2017 sob a coordenação de um dos pesquisadores do Educas. Esta iniciativa teve como objetivo "cartografar a constituição das relações de saber/poder, a formação, as práticas e os saberes dos professores dos cursos de licenciatura da UECE que ministram disciplinas destinadas à formação pedagógica" (CAVAIGNAC, 2018, p. 2). Nesse sentido, elegeu como objeto de estudo os processos formativos dos professores, apoiada na premissa de que "quando os docentes são reconhecidos pelos seus pares como os responsáveis por algum tipo de formação, devido às escolhas feitas, saberes específicos, formação ou práticas exercidas, os profissionais que são destacados assumem uma relação de saber/poder" (MAGALHÃES JUNIOR, 2014).

O estudo assumiu um desenho cartográfico, identificado como possibilidade fértil para delinear os percursos (desenhos) de formação dos professores da licenciatura. Os resultados da investigação compuseram um mapa de como trabalham os profissionais responsáveis pela formação pedagógica de novos professores, possibilitando subsidiar a tomada de decisão institucional visando melhorar a qualidade profissional do exercício docente na universidade. 
No âmbito da formação de recursos humanos, em particular de pesquisadores em educação, sobreleva-se a contribuição dessa investigação. Dados, por exemplo, do relatório de pesquisa do estágio pós-doutoral de Cavaignac (2018), ao apresentar uma "síntese" das produções acadêmicas desenvolvidos no âmbito da pesquisa 'Cartografia das relações de saber/poder dos professores das licenciaturas', destacam cinco trabalhos: 2 dissertações e três textos de qualificação de projetos de pesquisa dos cursos de Mestrado e Doutorado vinculadas ao PPGE/UECE, no caso os trabalhos de Miranda (2016), Santos (2017), Varela (2017), Maciel (2017) e Neta (2018). São produções que reforçam a asserção de que a caminhada associativa do Educas, aglutinando pesquisadores experientes e orientandos de graduação, pós-graduação e da Educação Básica, é potente.

O apanhado nas três linhas de pesquisa do Educas denota que, por diferentes vias, seus estudos se entrecruzam e aportam dados relevantes para a compreensão da formação de professores. Eles se somam e evidenciam a multiplicidade e complexidade de aspectos envoltos nesse campo de conhecimento e de investigação.

\section{A GUISA DE CONCLUSÃO}

A formação de professores, por diferentes ângulos, encontra-se no centro dos estudos e produções do EDUCAS, foco temático organicamente ligado a ênfase que este campo possui na UECE, tanto na graduação quanto na pós-graduação stricto sensu.

Nesses termos, o fomento a cultura de pesquisa no contexto da formação inicial e continuada de profissionais docentes se sobressai como principal contributo do trabalho desenvolvido no âmbito do Educas. Nesse sentido, destaca-se a participação ativa do grupo na implantação e consolidação do Programa de Pós-Graduação em Educação da UECE (conceito 5), que tem como área de concentração a formação de professores. A aprovação do Curso de Doutorado pela CAPES (em 04/2012) e, com ele, a constituição da linha de pesquisa "Formação e Desenvolvimento Profissional em Educação," é expressiva de sua contribuição.

Paralelo à formação de professores pesquisadores na pós-graduação stricto sensu, faz-se necessário destacar o investimento dos pesquisadores do Educas na iniciação à pesquisa cá e acolá, ou seja, na capital e seus arredores. Destes, muitos já se tornaram professores formadores de novos pesquisadores e outros estão atuando na Educação Básica ou na Educação Superior. Enfim, os resultados das pesquisas inventariadas nos doze anos de vida do Educas estão manifestos: a) No incremento da produção bibliográfica dos pesquisadores do Educas, o que tem fortalecido suas inserções nos programas de pós-graduação stricto sensu, seja como docentes permanentes, seja como colaboradores; b) Na consolidação de uma cultura de pesquisa em Educação na UECE, na criação e consolidação da pós-draduação em Educação"; c) Na continuidade e aprofundamento do escopo de estudos do Educas; d) Na formação de novos pesquisadores para a área educacional; e) No desenvolvimento de formação continuada articulado ao processo de produção do conhecimento. Os aspectos elencados denotam o potencial do processo associativo baseado no trabalho colaborativo entre pares, iniciantes e veteranos, no mundo da pesquisa científica. 
DOI https://doi.org/10.31639/rbpfp.v10i19.180

\section{REFERÊNCIAS}

ABBAgnANO, Nicola. Dicionário de Filosofia. Tradução da 4ª ed. São Paulo: Martins Fontes, 2000.

AGUIAR, Karen Cristina V. de. A história de vida evidenciada nas idéias de educadores do Ensino Fundamental no município de Fortaleza. Monografia (Pedagogia). Fortaleza: UECE/CED, 2007.

ARAÚJO, Sandra Regina Pires; FARIAS, Isabel Maria Sabino de. Professoras dos anos iniciais do Ensino Fundamental e seus saberes sobre pesquisa: entre os caminhos da formação e da prática profissional. In: FARIAS, Isabel Maria Sabino de; NÓBREGA-THERRIEN, Silvia Maria; MORAES, Lélia Cristina Silveira de (Orgs.). Formação e Desenvolvimento Profissional em Educação. São Luiz: EDUFMA, 2017, p.68-101.

BEZERRA, José Eudes Baima. A Intenção e o Gesto: Educação e Mudancismo no Ceará (1987-1991). Dissertação (Mestrado em Educação). Programa de Pós-Graduação em Educação Brasileira. Fortaleza: UFC, 1996.

BRASIL. MEC. CAPES. Plano Nacional de Pós-Graduação - PNPG 2011-2010. Brasília: DF: CAPES, 2010.

CARDOSO, Nilson de Souza; FARIAS, Isabel Maria Sabino de. Como ensina o professor de Ciências Biológicas que pesquisa? In: FARIAS, Isabel Maria Sabino de; NÓBREGA-THERRIEN, Silvia Maria; MORAES, Lélia Cristina Silveira de (Orgs.). Formação e Desenvolvimento Profissional em Educação. São Luiz: EDUFMA, 2017, p.102-124.

CASTRO, Solange Maria Santos. Profissão Professor no Ceará 1964-1985: percursos ambíguos da docência. Monografia (Pedagogia). Fortaleza: UECE/CED, 2007.

CAVAIGNAC, Monica Duarte. Desafios da Formação Docente: um estudo a partir dos percursos, saberes e práticas dos professores dos cursos de licenciatura da Universidade Estadual do Ceará - UECE. Relatório de Pesquisa. Estágio Pós-Doutoral. Fortaleza: UECE/PPGE, 2018.

CAVALCANTE, Maria Marina Dias; NUNES, João Batista Carvalho; FARIAS, Isabel Maria Sabino de (Orgs.). Pesquisa em Educação na UECE: um caminho em construção. Fortaleza: Edições Demócrito Rocha, 2002.

CONCEIÇÃO, Ariádine Custódio Vieira. A Carreira Docente (1930/1964): o que dizem os documentos oficiais? Monografia (Pedagogia). Fortaleza: UECE/CED, 2007.

ESTEVES, Maria Manuela. Prefácio. In: FARIAS, Isabel Maria Sabino de; JARDILINO, José Rubens Lima; SILVESTRE, Magali Aparecida; ARAÚJO, Regina Magna Bonifácio de. Pesquisa em Rede: diálogos de formação em contextos coletivos de conhecimento. Fortaleza: EdUECE, 2018, p. 13-19.

FARIAS, Isabel Maria Sabino de. A Atividade Docente no Telensino: um estudo acerca dos saberes mobilizados na prática pedagógica do Orientador de Aprendizagem. Dissertação (Mestrado em Educação). Programa de Pós-Graduação em Educação Brasileira. Fortaleza: UFC, 1997.

A cultura docente face à formação para a pesquisa: a gestão dos saberes na docência universitária. Relatório Técnico Final. Fortaleza: UECE/EDUCAS/CNPq, 2011, 280p. 
BEZERRA, José Eudes Baima. Melhoria da Aprendizagem na Escola de Ensino Médio: avanços, limites e perspectivas do PIBID no cenário da avaliação censitária. Projeto de Pesquisa. Fortaleza; UECE: EDUCAS, 2011.

. Do documento ao documento: recompondo seu lugar histórico. In: NÓBREGA-THERRIEN, S. M; FARIAS, I. M.S. de; NUNES, J. B. C. Pesquisa científica para iniciantes: caminhando no labirinto. Fortaleza; EdUECE, 2011, vol. III, p. 43-54.

; JARDILINO, José Rubens Lima; SILVESTRE, Magali Aparecida; ARAÚJO, Regina Magna Bonifácio de. Pesquisa em Rede: diálogos de formação em contextos coletivos de conhecimento. Fortaleza: EdUECE, 2018.

(Orgs.). Aprender a ser professor: aportes de pesquisa sobre o PIBID. Jundiaí:

Paco Editorial, 2015

Desenvolvimento Profissional Docente e Inovação Pedagógica: estudo exploratório sobre contribuições do PIBID. Projeto de Pesquisa em Rede - Programa Observatório da Educação/OBEDUC CAPES. Fortaleza: UECE. EDUCAS, 2012.

NÓBREGA-THERRIEN, Silvia Maria; MORAES, Lélia Cristina Silveira de (Orgs.). Formação e Desenvolvimento Profissional em Educação. São Luiz: EDUFMA, 2017.

; NUNES, Ana Ignez Belém Lima. Ofício de professor: trajetórias, idéias e práticas. Revista da Educação Pública, Cuiabá: EdUFMT, 2006, v. 15, nº. 28, p 69-84.

; ALBUQUERQUE, Maria Glaúcia Menezes Teixeira; MAGALHÃES JÚNIOR, Antonio Germano; BEZERRA, José Eudes Baima. Profissão Professor: política e memórias. Relatório Técnico de Pesquisa. Fortaleza: UECE. EDUCAS/CNPq, 2007, 193p.

; THERRIEN, Jacques; NÓBREGA-THERRIEN, Silvia Maria; SALES, José Albio Moreira. Formação de Professores no Estado do Ceará: a responsabilidade social da UECE. Revista Educação Brasileira, v. 33, p. 42-69, 2011.

SILVA, Silvina Pimentel. A Docência Universitária sob o prisma da integração ensino e pesquisa. Teresina: EDUFPI, 2014.

FURTADO, Bernardo Alves. Pesquisa em rede: análise preliminar dos grupos de pesquisa do CNPq em 2014. Radar n 45 - Junho de 2016. Disponível em: <Repositorio.ipea.gov.br/bitstream/11058/6879/1/Radar_n45_pesquisa.pdf>. Acessado em: 28 dez. 2017.

GÓMEZ, A. I. Pérez. La cultura escolar em La sociedad neoliberal. Madrid: Edicones Morata, 1998.

GURGEL, Maria Isabele P. A história de vida na construção da identidade do professor. Monografia (Pedagogia). Fortaleza: UECE/CED, 2008.

HARGREAVES, Andy. Profesorado, cultura y postmodernidad: cambian lostiempos, cambia el profesorado. Madrid: Ediciones Morata, 1999. 
HOUAISS, Antônio; VILLAR, Mauro de Salles. Dicionário Houaiss da língua portuguesa. Instituto Antônio Houaiss de Lexicografia e Banco de Dados da Língua Portuguesa S/C Ltda. $1^{\text {a }}$ Ed. Rio de Janeiro: Objetiva, 2009.

JARDILINO, José Rubens Lima. Educação e Protestantismo - estudo sobre os fundamentos da educação na Reforma Protestante: a correspondência de João Calvino (1536-1564). Projeto de Estágio Pós-Doutoral. Ouro Preto, UFOP, 2015

KOSIK, K. A Dialética do Concreto. Rio de Janeiro: Paz e Terra, 1976.

LE GOFF, J. História e memória. Tradução Bernardo Leitão [et. all.]. $4^{a}$ ed. Campinas, São Paulo: Editora da UNICAMP, 1996 (Coleção Repertórios).

MACHADO, Nilson José. A Universidade e a organização do conhecimento: a rede, o tácito, a dádiva. Estudos Avançados, vol.15 no.42, São Paulo May/Aug. 2001. Disponível em: http://www.scielo.br/scielo. php?script=sci_arttext\&pid=S0103-40142001000200018. Acessado em: 31/12/17.

MACIEL, Alessandra de Oliveira. Cartografia da formação, saberes e práticas avaliativas de professores no curso de matemática. Relatório de Qualificação de Projeto de Dissertação. (Educação). Universidade Estadual do Ceará. Centro de Educação. Programa de Pós-Graduação em Educação. Fortaleza-Ce, 2017.

MAGALHÃES JÚNIOR, Antonio Germano; FARIAS, Isabel Maria Sabino de. Memórias e Cotidiano: os escritos de Amália Xavier de Oliveira sobre a escola Normal Rural de Juazeiro do Norte (1934-1946). In: VASCONCELOS, J. G.; NASCIMENTO, Jorge Carvalho (Org.). História da Educação no Nordeste Brasileiro. Fortaleza: Edições UFC, 2006, p. 77-90.

FARIAS, Isabel Maria Sabino de. Ruralismo, Memórias e Práticas Educativas no Cotidiano da Primeira Escola Normal Rural do Brasil: a Escola Normal Rural de Juazeiro do Norte - Ce (1934 - 1946). In: WERLE, F. O. C. (Org.). Educação Rural em perspectiva internacional: instituições, práticas e formação do professor. ljuí: Ed. Unijuí, 2007, p. 53-78.

Cartografia das relações de saber/poder dos professores das licenciaturas. Projeto de Pesquisa. Edital Universal do CNPQ 14/2014. Fortaleza: UECE, 2014.

Cotidiano das práticas formativas de professores em Fortaleza: mitos e ritos na constituição de uma cultura profissional no período republicano. Projeto de Pesquisa. Fortaleza: UECE, 2011.

Vigilância, Transgressão e Punição: Memórias de ex-alunas de escolas católicas de formação de educadoras (1964-1969). Tese (Doutorado em Educação). Programa de Pós-Graduação em Educação Brasileira. Fortaleza: UFC, 2003.

MIRANDA, Augusto Ridson de Araújo. Formação, saberes e práticas dos professores da área de Ensino de História no Curso de História da UECE em Fortaleza. Dissertação (Educação). Universidade Estadual do Ceará. Centro de Educação. Programa de Pós-graduação em Educação. Fortaleza-Ceará, 2016. 
MOREIRA, Jonathan Rosa; VILAN FILHO, Jayme Leiro; MUELLER, Suzana Pinheiro Machado. Características e produção científica dos grupos de pesquisa do CNPq/DGP nas áreas de Ciência da Informação e Museologia (1992 - 2012). Perspectivas em Ciência da Informação, v.20, n.4, p.93-106, out./dez. 2015.

MILLS, C. W. Apêndice: do artesanato intelectual. In: A imaginação sociológica. $2^{\mathrm{a}}$ ed. Rio de Janeiro:Zahar, 1969.

NETA, Maria de Lourdes da Silva. O conhecimento avaliativo dos docentes dos cursos de pedagogia: cartografia dos saberes, práticas e formação. Relatório de Qualificação de Tese (Doutorado em Educação). Universidade Estadual do Ceará. Centro de Educação. Programa de Pós-graduação em Educação. Fortaleza-Ce, 2018.

NÓBREGA-THERRIEN, S. M; FARIAS, I. M. S. de; SILVA, Silvina Pimentel. O grupo de estudo como estratégia de formação e produção de conhecimento sobre desenvolvimento profissional em educação. In: FARIAS, Isabel Maria Sabino de; NÓBREGA-THERRIEN, Silvia Maria; MORAES, Lélia Cristina Silveira de (Orgs.). Formação e Desenvolvimento Profissional em Educação. São Luiz: EDUFMA, 2017, p.142-170.

NOGUEIRA, Delane Lima. A Profissão Professor no Ceará dos anos 1930. Monografia (Pedagogia). Fortaleza: UECE/CED, 2005.

Amália Xavier e a Escola Normal Rural de Juazeiro do Norte: registros sobre a constituição de uma cultura docente para a educação no campo. $1^{\text {a }}$ ed. Fortaleza: editora IMEPH, 2011.

NUNES, Ana Ignez Belém Lima. A professora alfabetizadora: caminhos e descaminhos na construção de uma identidade. Dissertação (Mestrado em Educação). Programa de Pós-Graduação em Educação Brasileira. Fortaleza: UFC, 1995.

PERONI, V. Política Educacional e papel do Estado: no Brasil dos anos 1990. São Paulo: Xamã, 2003.

RAMOS, Jeannette Filomeno Pouchain. Gestão do Projeto Educativo da Escola de Ensino Médio nas Trilhas das Mudanças. Projeto de Pesquisa. Edital Universal MCT/CNPq 14/2007. Fortaleza: EDUCAS/UECE, 2007.

Gestão por Resultado na Educação: a responsabilização e o regime de colaboração na promoção do direito à educação no Ceará (1995-2010). Projeto de Pesquisa. Edital Universal MCT/CNPq 13/2014. Fortaleza: EDUCAS/UECE, 2014.

ROCHA, Cláudio César Torquato. Saberes da docência aprendidos no PIBID: Um estudo com futuros professores de Sociologia. $1^{a}$ edição. Jundiaí: Paco Editorial, 2015.

FALCÃO, Giovana Maria Belém; FARIAS, Isabel Maria Sabino de. Desenvolvimento profissional de docentes da Educação Básica: o que contam professores supervisores do PIBID no Ceará?. In: FARIAS, Isabel Maria Sabino de; JARDILINO, José Rubens Lima; SILVESTRE, Magali Aparecida (Orgs.). Aprender a ser professor: aportes de pesquisa sobre o PIBID. Jundiaí: Paco Editorial, 2015, p. 96-116.

RUF 2017. Ranking de universidades. Disponível em: https://ruf.folha.uol.com.br/2017/ranking-de-universidades/. Acessado em 30/05/18. 
SANTOS, Maria Terla Silva Carneiro dos. Saberes, práticas e formação: uma cartografia dos professores da área de "História e Ensino" da FECLESC/ UECE. Dissertação (Educação). Universidade Estadual do Ceará. Centro de Educação. Programa de Pós-Graduação em Educação. Fortaleza-Ceará, 2017.

SILVA, Mirelle Araújo. O Pensamento Pedagógico da Escola Nova na Proposta de Formação da Escola Normal Rural de Juazeiro do Norte. Monografia (Pedagogia). Fortaleza: UECE/CED, 2007.

O Lavrador: a função do jornal na formação do professor ruralista de Juazeiro do Norte. $1^{\text {a }}$ ed. Fortaleza: editora IMEPH, 2011.

SILVA, Silvina Pimentel. Docência universitária e pesquisa: contradições e possibilidades. Relatório do Estágio Pós-Doutoral. Universidade de Brasília/UNB, Brasília: PPGE, 2013.

O Professor do Ensino Superior e a Pesquisa: Qual relação e prática pedagógica?. Projeto de Pesquisa. Fortaleza: EDUCAS/UECE, 2011.

Os Cursos de Licenciatura como formadores de professores: em que se constituem as bases da formação para a docência na Educação Básica?. Projeto de Pesquisa. Fortaleza: EDUCAS/UECE, 2014.

A Formação Continuada no exercício da docência em contextos da universidade: o que pensam os professores?. Projeto de Pesquisa. Fortaleza: EDUCAS/UECE, 2017.

SILVEIRA, Clarice Santiago; NÓBREGA-THERRIEN, Silvia Maria; AZEVEDO, Maria Raquel de Carvalho. A pesquisa na formação do professor: estratégia de melhoria do seu campo teórico e prático. In: FARIAS, Isabel Maria Sabino de; NÓBREGA-THERRIEN, Silvia Maria; MORAES, Lélia Cristina Silveira de (Orgs.). Formação e Desenvolvimento Profissional em Educação. São Luiz: EDUFMA, 2017, p.25-67.

SHIROMA, O. E.; MORAIS, M. C. M. de; EVANGELISTA, O. Política Educacional. Rio de Janeiro: DP\&A, 2000.

THOMPSON, P. A voz do passado: história oral. Tradução Lólio Lourenço de Oliveira. $2^{\mathrm{a}}$ ed. Rio de Janeiro: Paz e Terra, 1998.

VARELA, Sarah Bezerra Luna. Docência universitária em cursos de licenciatura: cartografias de percursos formativos, constituição de saberes e vivências de práticas pedagógicas. Relatório de Qualificação de Tese (Doutorado em Educação). Universidade Estadual do Ceará. Centro de Educação. Programa de Pós-graduação em Educação. Fortaleza-Ce, 2017. 
